\title{
Brucella spp noncanonical LPS: structure, biosynthesis, and interaction with host immune system

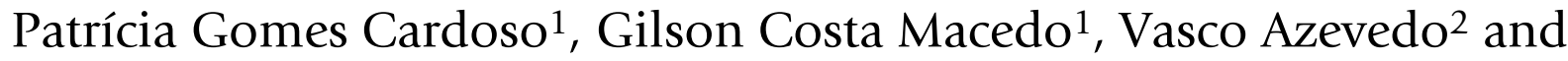 Sergio Costa Oliveira*1
}

Address: ${ }^{1}$ Department of Biochemistry and Immunology, Biological Sciences Institute, Federal University of Minas Gerais, Belo Horizonte-Minas Gerais, Brazil and 2Department of General Biology, Biological Sciences Institute, Federal University of Minas Gerais, Belo Horizonte-Minas Gerais, 30161-970, Brazil

Email: Patrícia Gomes Cardoso - pattygomes@yahoo.com; Gilson Costa Macedo - gcm@icb.ufmg.br; Vasco Azevedo - vasco@icb.ufmg.br; Sergio Costa Oliveira* - scozeus@icb.ufmg.br

* Corresponding author

Published: 23 March 2006

Microbial Cell Factories2006, 5:13 doi:10.1186/1475-2859-5-13
Received: 30 December 2005

Accepted: 23 March 2006

This article is available from: http://www.microbialcellfactories.com/content/5/1//3

(c) 2006Cardoso et al; licensee BioMed Central Ltd.

This is an Open Access article distributed under the terms of the Creative Commons Attribution License (http://creativecommons.org/licenses/by/2.0), which permits unrestricted use, distribution, and reproduction in any medium, provided the original work is properly cited.

\begin{abstract}
Brucella spp. are facultative intracellular pathogens that have the ability to survive and multiply in professional and non-professional phagocytes, and cause abortion in domestic animals and undulant fever in humans. Several species are recognized within the genus Brucella and this classification is mainly based on the difference in pathogenicity and in host preference. Brucella strains may occur as either smooth or rough, expressing smooth LPS (S-LPS) or rough LPS (R-LPS) as major surface antigen. This bacterium possesses an unconventional non-endotoxic lipopolysaccharide that confers resistance to anti-microbial attacks and modulates the host immune response. The strains that are pathogenic for humans (B. abortus, B. suis, B. melitensis) carry a smooth LPS involved in the virulence of these bacteria. The LPS O-chain protects the bacteria from cellular cationic peptides, oxygen metabolites and complement-mediated lysis and it is a key molecule for Brucella survival and replication in the host. Here, we review i) Brucella LPS structure; ii) Brucella genome, iii) genes involved in LPS biosynthesis; iv) the interaction between LPS and innate immunity.
\end{abstract}

\section{Background}

Brucellae are Gram-negative cocccobacilli, facultative intracellular bacterial pathogens of both humans and animals. The bacteria penetrate the mucosa of the nasal, oral, or pharyngeal cavities and are phagocytized by host macrophages, where survival and replication occurs. Brucellosis is a zoonotic disease that is difficult to diagnose and treat that causes heavy economic losses and human suffering, characterized by undulant fever that, if untreated, can develop into a chronic infection with symptoms persisting for several months. Chronic infections may result in infection of secondary tissues, including heart and brain.
Symptoms may also recur years after the original infection. The pathological manifestations of brucellosis are diverse and include arthritis, endocarditis, and meningitis in humans, while animal brucellosis is characterized by spontaneous abortion [1]. Six species are recognized within the genus Brucella: B. abortus, B. melitensis, B. suis, $B$. ovis, $B$. canis, and B. neotomae. This classification is mainly based on the difference in pathogenicity and in host preference [2]. The main pathogenic species worldwide are $B$. abortus, responsible for bovine brucellosis; $B$. melitensis, the main etiologic agent of ovine and caprine brucellosis, a disease that causes abortion in ewes and 
goats resulting in huge economic losses, particularly in Mediterranean countries and B. suis responsible for swine brucellosis. B. abortus infection is acquired by humans through contact with infected livestock and consumption of unpasteurized dairy products. B. ovis and B. canis are responsible for ram epididymitis and canine brucellosis, respectively [3]. For B. neotomae only strains isolated from desert rats have been reported. Brucella strains have also been isolated from a great variety of wildlife species such as bison, elk, feral swine, foxes, hares, African Buffalo, reindeer, and caribou [4]. Recently, two new species have been proposed to be added to this genus, Brucella cetaceae and Brucella pinnipediae isolated from marine mammals, cetaceans and pinnipeds, respectively [5,6]. Distinction between species and biovars is currently performed by differential tests based on phenotypic characterization of lipopolysaccharide antigens, phage typing, dye sensitivity,
$\mathrm{CO}_{2}$ requirement, $\mathrm{H}_{2} \mathrm{~S}$ production, and metabolic properties [7].

Additionally, Brucella can be used as a biological weapon since transmission through a spray is possible, as has been reported with human contamination during abortion of infected animals or bacterial spraying in laboratories [8]. The bacteria is highly contagious and it is suggested that 10 to 100 bacteria would be sufficient to produce a contaminating spray for humans. Several countries have been suspected of studying the agent as a biological weapon, but to date, no use of Brucella in a bioterrorist attack has been reported.

In this article, we review the importance of the lipopolysaccharide in Brucella virulence, discussing the LPS chemical composition, the Brucella genome, the genes involved

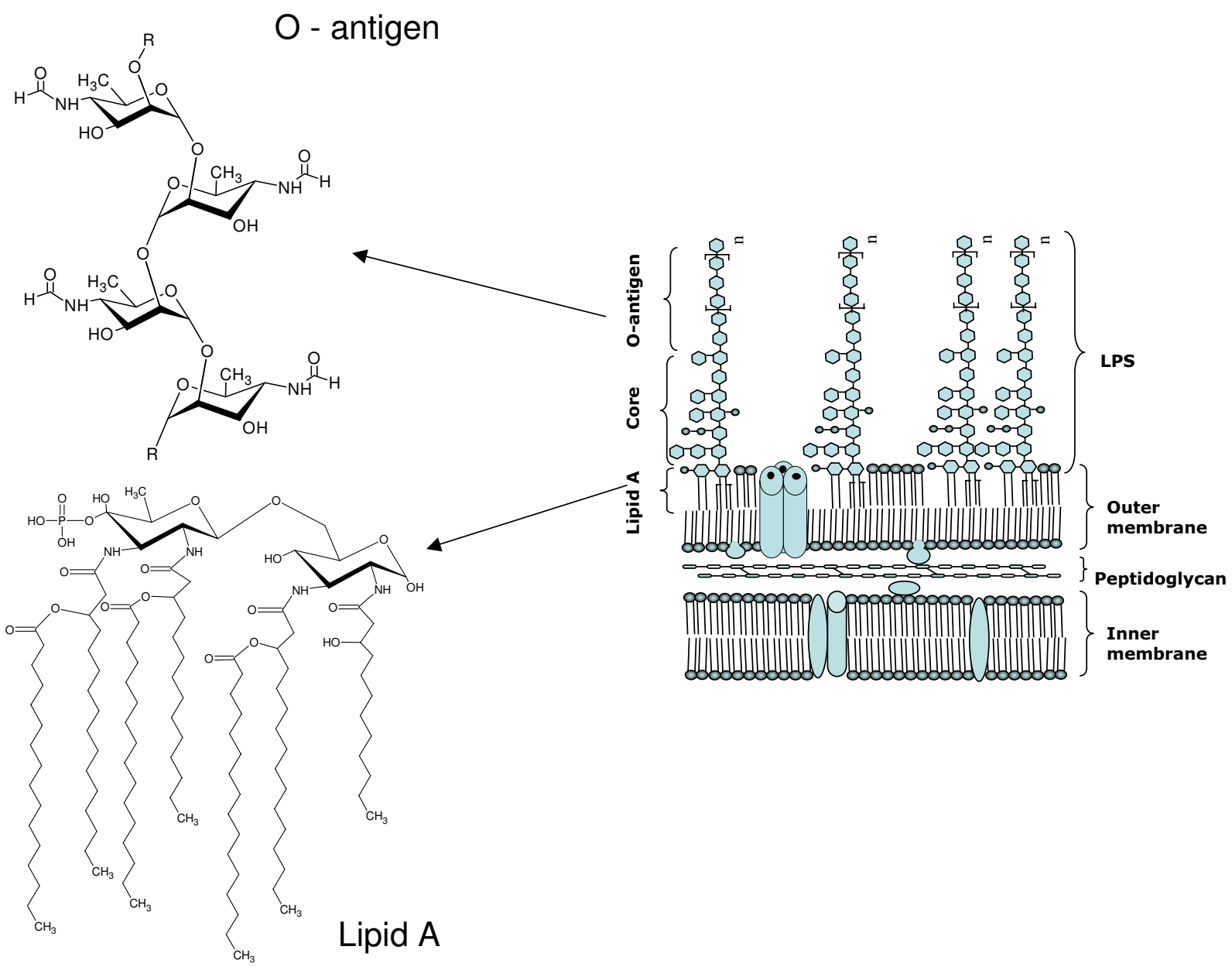

Figure I

Schematic structure of lipopolysaccharide (LPS) from Brucella spp. 
in LPS biosynthesis, and the interaction between LPS and innate immunity.

\section{Chemical composition of lipopolysaccharide from different Brucella strains}

Several studies on virulence factors were directed at the main components of the outer membrane. The outer membrane contains the lipopolysacharide (LPS) that is the Brucella major virulence factor. Lipopolysaccharide is vital to both the structural and functional integrity of the Gram-negative bacterial outer membrane. Ubiquitously expressed by all Gram-negative bacteria, and containing several well-conserved domains, LPS also serves as one of the primary targets of the innate arm of the mammalian immune system. Brucella possesses a peculiar non-classical LPS as compared with classical LPS from enterobacteria such as Escherichia coli [9]. The LPS was identified as a major virulence determinant of Brucella recognized for its role in virulence when naturally occurring isolates lacking LPS showed reduced survival. LPS has three domains: lipid $\mathrm{A}$, the core oligosaccharide, and the $\mathrm{O}$-antigen or $\mathrm{O}$ side chain (Figure 1). The O-polysaccharide of smoothtype Brucella LPS (S-LPS) is an unbranched homopolymer of 1,2-linked4,6-dideoxy-4-formamido- $\alpha$-D-mannopyranosyl usually with an average chain length of 96 to 100 glycosyl subunits [10]. The O-polysaccharide is linked to a core oligosaccharide composed of mannose, glucose, 2-amino-2,6-dideoxy-D-glucose (quinovosamine), 2-amino-2-deoxy-D-glucose (glucosamine), 3deoxy-D-manno-2-octulosonic acid (KDO) and unidentified sugars. The lipid A, linked to the core oligosaccharide, contains 2,3-diamino-2,3-dideoxy-D-glucose (diaminoglucose) as backbone, amide and ester-linked long chain saturated $\left(\mathrm{C}_{16: 0}\right.$ to $\left.\mathrm{C}_{18: 0}\right)$ and hydroxylated (3OH- $\mathrm{C}_{12: 0}$ to 29-OH- $\mathrm{C}_{30: 0}$ ) fatty acids [11]. The hydrophobic lipid A region constitutes mostly the outer coating of the outer membrane and is responsible for many of the endotoxic properties attributed to LPS [12]. Thermotropic phase behaviour [13] and immunochemical analysis [14] of B. abortus and B. melitensis lipid A suggest a disaccharide backbone molecule linked in a $\beta 1-6$ configuration. Ethanolamine, neutral sugars and ester-linked acyl-oxyacyl fatty acids are not found, and phosphate is absent or present in reduced quantities [11]. Brucella lipid A contains strongly bound outer membrane protein fragments that are not removed by conventional procedures used to release the lipid-A-associated protein of enterobacterial LPS $[11,14]$. The heterogeneity of enterobacterial LPS is well known to be related to the length of its O-polysaccharide and different chemical substitutions in the core oligosaccharide and lipid A [15]. In enterobacterial lipid A, the degree of heterogeneity depends upon the different combinations in which amide and ester-linked fatty acids, phosphate, neutral sugars, ethanolamine and different types of backbone amino sugars occur in the molecule
[16]. In Brucellae lipid A, the degree of heterogeneity may depend mainly on the various fatty acid substitutions. The absence of backbone constituents (other than lipids) and ester-linked acyl-oxyacyl residues in Brucella lipid A might account for the restricted number of variants as compared to enterobacterial lipid A. Determination of the intrinsic heterogeneity in Brucella LPS is important to explain in a more realistic perspective its chemical nature and biological behavior. For practical purposes, this is significant, since LPS is the most relevant antigen during infection and vaccination. In addition, LPS and LPS-related molecules are extensively used in immunological studies and in the diagnosis of brucellosis [17].

\section{Brucella genomes}

Recently, the genome sequences of the $B$. melitensis, $B$. suis and $B$. abortus became available [18-20]. The genomes of B. suis, B. melitensis, and B. abortus are very similar in sequence, organization, and structure. Few fragments are unique among the genomes [20]. Although many aspects of its biology remain to be understood, the sequencing and annotation of its genome paved the way for a highly comprehensive and rapid analysis of its proteome. Comparative genomics provide insights into aspects of Brucella virulence that were only suspected before. The era of postgenomic technology offers new and exciting opportunities to understand the complete biology of different $\mathrm{Bru}$ cella species. At the proteome level, extensive metabolic differences were found between the B. melitensis reference strain $16 \mathrm{M}$ and its vaccine strain Rev 1 . Similarly, laboratory grown $B$. melitensis can be distinguished from $B$. abortus by just looking at their proteome [21]. Using the complete genome sequence of Brucella melitensis, Dricot et al. [22] generated a database of protein-coding ORFs and constructed an ORFeome library of 3091 Gateway entry clones, each containing a defined ORF. This first version of the Brucella ORF (Version 1.1) provides the coding sequences in a user-friendly format amenable to highthroughput functional genomic and proteomic experiments, as the ORFs are conveniently transferable from the entry clones to various expression vectors by recombinational cloning. The cloning of the Brucella ORFeome v.1.1 should help to provide a better understanding of the molecular mechanisms of virulence, including the identification of bacterial protein-protein interactions, but also interactions between bacterial effectors and their host targets.

The genome of B. melitensis strain $16 \mathrm{M}$ contain 3,294,935 bp distributed over two circular chromosomes of $2,117,144$ bp and 1,177,787 bp encoding 3,197 open reading frames (ORFs). The origins of replication of the two chromosomes are similar to those of other proteobacteria. Housekeeping genes, including those involved in DNA replication, transcription, translation, core metabo- 
Table I: Genes encoding O-antigen biosynthesis in Brucella spp.

\begin{tabular}{ll}
\hline Gene & Product \\
\hline Gmd & GDP-mannose dehydratase \\
Per & Perosamine synthetase \\
Pgm & Phosphoglucomutase \\
Pmm & Phosphomannomutase \\
ManB & Mannose isomerase \\
ManC & Mannose guanylyltransferase \\
Wzm & O-antigen export permease \\
Wzt & ATP-binding protein \\
WbkB & no similarity to known genes \\
WbkC & Methionyl tRNA formyltransferase \\
WbkA & N-formyl-perosaminyltransferase \\
\hline
\end{tabular}

lism, and cell wall biosynthesis, are distributed on both chromosomes [21]. Screens for transpositional mutants attenuated in infection models yielded 184 mutants, suggesting that these genes have a function in the infection process [23]. The B. suis 1330 genome consists of two circular chromosomes of $2,107,792$ bp and 1,207,381 bp [19]. A total of 2,185 and 1,203 ORFs were identified on chromosomes I and II, respectively. Comparison of the $B$. suis genome with that of the $B$. melitensis genome revealed extensive similarity and gene synteny [21]. The majority (>90\%) of B. suis and B. melitensis genes share $98-100 \%$ identity at the nucleotide level. The more variable genes ( $<95 \%$ identity) consist primarily of hypothetical genes, as well as a UreE urease component, and probable surfaceexposed genes such as outer membrane proteins, membrane transporters, a putative invasin, and ShdA-like adhesins. These more variable genes may significantly contribute to the differences in pathogenicity or host preference between these two organisms. The high degree of similarity between the $B$. suis and $B$. melitensis genomes at both the gene and nucleotide level is consistent with the proposition that Brucella species should be grouped as biovars of a single species.

The genome of B. abortus biovar 1 (Strain 9-941) have 3.3 $\mathrm{Mb}$ and is composed of two circular chromosomes of 2,124,242 (Chr I) and 1,162,780 bp (Chr II) [20]. The chromosome sequences of $B$. abortus 9-941 were assigned the same strand orientation and origin as those of $B$. suis. The B. abortus genome contains 3,296 ORFs annotated as genes, 2,158 on Chr I and 1,138 an Chr II. This is similar to the annotated ORF counts for $B$. suis $(3,388)$ and $B$. melitensis $(3,197)$. The genome of $B$. abortus shared more fragments with $B$. suis and $B$. melitensis than $B$. suis and $B$. melitensis did with each other. $B$. abortus shared more fragments with $B$. melitensis than $B$. suis. Two fragments shared by $B$. suis and B. melitensis were not found in B. abortus. A 2,774-bp fragment encoding a probable surface protein and two partial ORFs with homology to the insertion sequences IS711 and ISBm 1 is missing from $B$. abortus. The second fragment is a $25-\mathrm{kb}$ sequence that may be involved in polysaccharide synthesis and was predicted by Vizcaino et al. [24] to potentially affect phenotypes of brucellae, such as host preference.

\section{Genes involved in LPS biosynthesis}

The majority of studied genes and their products involved in Brucella LPS biosynthesis are those related to O-chain synthesis (Table 1). The large number of attenuated mutants with a structural defect in their lipopolysaccharide (LPS) confirms the importance of this molecule in Brucella virulence. In spite of the importance of LPS in the Brucella life cycle, very little is known about the metabolic pathways and enzymes required to synthesize it. Certain strains carry mutations in the genes involved in O-chain biosynthesis and attachment and are termed 'rough mutants'(R) strains to differentiate them from the wildtype 'smooth' (S) strains that express O-chain-bearing LPS. Historically, the search for rough mutants was performed in two ways: by a spontaneous phenomenon known as phase variation, in which rough variants appear in culture by a mechanism not well understood [7], or by successive passages in different culture media with searching for spontaneously rough phenotypes. These procedures gave a high number of rough mutants. All of them are avirulent in animal models, but in most cases the parental strain is not available. B. abortus, B. melitensis, and $B$. suis strains may occur as either smooth or rough, expressing smooth LPS (S-LPS) or rough LPS (R-LPS) as major surface antigen, while $B$. ovis and $B$. canis are two naturally R species, expressing R-LPS as major surface antigen. Generally these mutants are less virulent than the wild type, with the exception of those of Brucella ovis and $B$. canis, which are rough but virulent. It is accepted that rough mutants are more sensitive to lysis mediated by complement, and probably this is the main reason why most rough variants have an avirulent phenotype in animal models. To date the question about the capacity of rough mutants to replicate intracellularly is not solved. Some authors have reported that smooth LPS is essential for intracellular survival [25], for example, the vaccine strain RB51 exhibits loss of virulence and cannot replicate within macrophages [26]. On the other hand, there are some reports in which genetically characterized rough mutants did not loose the capacity to replicate intracellularly despite the total absence of the O-antigen [27]B. abortus strain RB51 is a stable rough (R) mutant derived from the standard smooth (S) virulent strain 2308. This rough mutant strain that does not contain the O-antigen (O polysaccharide chain of the smooth LPS) is attenuated in its virulence compared to their smooth virulent parental strain [27]. Even though the Brucella RB51 rough strain has been widely used as a live vaccine, it induces lower protection compared to the smooth vaccine strain S19 [28]. At similar concentrations, the Brucella vaccine strain 
S19 induces higher protection than the $\mathrm{R}$ vaccine strain (RB51). The lack of protective antibodies to the O-side chain of the LPS in animals immunized with $B$. abortus RB51 may explain in part why the R strain induces lower protection against infection [29]. A major problem in animal vaccination against brucellosis with currently used live attenuated smooth Brucella strains, such as B. melitensis strain Rev.1 for sheep and goats and B. abortus strain S19 for cattle, is the fact that vaccinated animals cannot be clearly differentiated from infected animals by the current serological tests. Further, these strains may induce abortions when used in pregnant animals and are virulent for humans. These tests are indeed based on detection of antibody to S-LPS that is immunodominant in the serological responses of both infected and vaccinated animals.

Below, we describe the main genes involved in LPS biosynthesis and the role of their encoding products.

\section{Perosamine synthetase(per)}

Godfroid et al. [30] described molecular analysis of the genes required for the synthesis of the O-antigen of $\mathrm{Bru}$ cella melitensis $16 \mathrm{M}$. The perosamine synthetase gene was cloned and sequenced. In $V$. cholerae O1, perosamine is synthesized from fructose 6-phosphate via four intermediates: mannose 6-phosphate, mannose 1-phosphate, GDP-mannose, and 4-keto-6-dideoxymannose. Ultimately, this final product is converted to GDP-perosamine by the perosamine synthetase [31]. Because the last step of the perosamine synthesis pathway is identical for $V$. cholerae and $B$. melitensis, it was assumed that the earlier steps might be similar or identical for these two organisms. In Brucella, the GDP-perosamine would then serve as a substrate for the addition of a formyl group and could then be polymerized into the O-antigen, translocated to the periplasm, transferred to the lipid A-core oligosaccharide, and exported to the cell surface. The disruption of per (B3B2 mutant) totally disabled the Oside chain biosynthesis of $B$. melitensis $16 \mathrm{M}$. The mutation was recreated by gene replacement, indicating that the mutant phenotype was due to the transposon insertion rather than to spontaneous mutation [30]. Indeed, such a disruption prevented any $\mathrm{O}$-side chain production, not only at the surface but also in the cytoplasm of the bacteria indicating that the mutation does not affect the transport of the O-side chain to the outer membrane but does affect an earlier stage of biosynthesis.

\section{Phosphomannomutase (pmm or manB)}

Allen et al. [27] to better characterize the role of O-antigen in virulence and survival used transposon mutagenesis to generate $B$. abortus rough mutants defective in O-antigen presentation. A mutant strain was characterized by a truncated rough LPS and DNA sequence analysis of this mutant revealed a transposon interruption in the gene encoding phosphomannomutase ( $p m m$ or manB), suggesting that this activity may be required for the synthesis of a full-length core polysaccharide in addition to O-antigen. This gene is responsible for the interconversion of mannose-6-phosphate and mannose-1-phosphate. In Brucella, mannose is both an important precursor in the $\mathrm{O}$-antigen biosynthetic pathway and in the production of the inner core moiety of LPS [32].

\section{Mannosyltransferases (wbkA, WbdA, B and C)}

$B$. abortus genes involved in chronic infection were identified by assessing the ability of 178 signature-tagged mutants to establish and maintain persistent infection in mice [33]. Each mutant was screened for its ability to colonize the spleens of mice at 2 and 8 weeks after inoculation. A mutant with defects in establishing chronic infection which carried a transposon insertion in a B. abortus homologue of Brucella melitensis $w b k A$, encoding a Nformyl-perosaminyltransferase that functions in the biosynthesis of $\mathrm{O}$-antigen, was the most highly attenuated. In E. coli O9a polysaccharide is polymerised by the action of three different mannosyltransferases WbdA, B and C [34]. In this scheme, WbdC transfers a mannose to the endogenous acceptor (GlcNAc-pyrophosphoundecaprenol). This reaction initiates the growth of the polysaccharide chain and provides the acceptor for subsequent progressive chain elongation by the sequential activities of $\mathrm{WbdB}$, transferring successive mannosyl units into the 3 position, and of WbdA, transferring successive mannosyl units at the 2 position of the previous mannose. On the basis of this scheme, the presence of $\alpha-1,2$ and $\alpha-1,3$ linkages in the LPS O-side-chain of Brucella suggests the existence of at least two $\mathrm{N}$-formyl-perosaminyltransferases, WbkA and WboA. The WbkA could interact with WboA to elongate the Brucella LPS O-side-chain by $\alpha-1,2$ and $\alpha-1,3$ links. The $w b o A$ gene that encodes a glycosyltransferase, an enzyme also essential for the biosynthesis of the O-side chain in B. abortus was characterized by McQuiston et al. [35]. The disruption of the $w b o A$ gene in smooth strains $B$. abortus 2308, B. melitensis $16 \mathrm{M}$ and B. suis biovar 4 resulted in conversion to a rough phenotype and attenuated [28]. Vemulapalli et al. [36] discovered that the wboA gene is interrupted by an IS711 element in B abortus vaccine strain RB51. The complementation of RB51 with a functional $w b o A$ gene resulted in O-antigen production but did not result in reversion to the smooth phenotype and did not affect attenuation, suggesting that RB51 contains an additional genetic mutation(s) that probably affects either the export of $\mathrm{O}$-antigen to the bacterial surface, the coupling of $\mathrm{O}$-antigen to core lipopolysaccharide, or both [37]. Two rough mutant strains RA1 and VTRM1 derived from virulent $B$. abortus 2308 or $B$. melitensis $16 \mathrm{M}$, respectively have identical mutations $w b o A$ gene. RA1 strain was more sensitive to the bactericidal action of nonimmune human serum and more com- 
plement components were deposited on its surface than on strain VTRM1 [38]. Similar species-specific differences in both complement deposition and complement-mediated killing were also observed when strain RA1 was compared with another rough mutant of $B$. melitensis, WRR51. Strain WRR51 was derived from $B$. melitensis strain $16 \mathrm{M}$ by replacement of the internal region of the $w b o A$ gene with an antibiotic resistance cassette instead of having a transposon insertion on this gene, as in the case of VTRM1 or RA1. There were no significant differences in either complement deposition or killing between VTRM1 and WRR51 [39]. Both strains were less susceptible than RA1 to the deposition of complement and complement-mediated killing. The LPS of strains RA1 and RB51 with the LPS of strain 2308 were compared and silver staining indicated that no O-side chain was associated with LPS of strains RA1 or RB51, and compositional analysis of smooth and rough $B$. abortus LPS revealed that 2-keto-3deoxy-D-manno-2-octulosonic acid (KDO) was the predominant glycose in the rough LPS [35]. Vizcaíno et al. [40] studying DNA polymorphism in the omp25/omp31 family of Brucella spp., identified a $15.1 \mathrm{~kb}$ fragment absent in Brucella ovis. The region absent from B. ovis suggests that this DNA fragment is a genomic island acquired by the Brucella ancestor by horizontal transfer and later deleted from B. ovis. This deletion includes $w b o A$ and two other genes that might be involved in the LPS synthesis. Absence of these genes in B. ovis may explain, at least in part, the rough phenotype naturally displayed by this Brucella species. The complementation of rough $B$. ovis PA with plasmids bearing $w b o A$, bearing $w b o A$ and the downstream gene potentially encoding a mannosyltransferase or bearing almost the entire $15.1 \mathrm{~kb}$ DNA fragment deleted in $B$. ovis strains did not confer a smooth phenotype, as shown by the lack of reactivity with a MAb specific for the Brucella spp S-LPS. This finding suggests that other genes required for the synthesis of S-LPS located at other chromosomal loci are affected in B. ovis. It seems clear that removal of the $15.1 \mathrm{~kb}$ genomic island from the smooth Brucella strains would reduce their virulence, since it was shown that the Tn5-disruption of $w b o A$ reduces survival of $B$. abortus in mice [35]. It would be interesting to determine how the complementation of $B$. ovis with the deleted genomic island would affect the virulence of this Brucella species.

\section{Phosphoglucomutase (pgm)}

The gene encoding for phosphoglucomutase $(\mathrm{pgm})$ is involved in O-antigen biosynthesis in B. abortus [41]. This gene is absolutely necessary for the biosynthesis of ADPglucose, UDP-glucose, and UDP-galactose, the donors of glucose or galactose for the biosynthesis of molecules containing these sugars. The predicted protein is $74.7 \%$ identical to its homologue in Agrobacterium tumefaciens but is not part of the glycogen operon as it is in Agrobacterium. B. abortus LPS O-antigen is a homopolymer of perosamine, a derivative of mannose that is synthesized through GDPmannose, thus, a pgm mutant of this species would not be impaired in the synthesis of GDP-perosamine, the sugar donor of $\mathrm{O}$-antigen subunits. Insertional mutagenesis of pgm was carried out introducing a gentamicin-resistant gene within the $B$. abortus pgm gene and the electrophoretic profile of the LPS extracted from this mutant strain indicated lack of the O-antigen. This mutant was unable to survive in mice but replicates in HeLa cells, indicating that the complete LPS is not essential either for invasion or for intracellular multiplication. This behavior suggests that the LPS may play a role in extracellular survival in the animal, probably protecting the bacteria against complement-mediated lysis, but is not involved in intracellular survival. The fact that the mutant replicates at a lower rate is not necessarily a consequence of the rough phenotype, since the absence of pgm affects many other components of the cell wall, such as, for example, the synthesis of $\beta(1,2)$ cyclic glucan [42]. Sequence analysis of the regions upstream and downstream of Brucella pgm revealed no significant homology to any gene in the database, which was surprising since in A. tumefaciens and Rhizobium loti, pmg is part of the glycogen operon.

\section{ABC type transporters (Wzm and Wzt)}

Godfroid et al. [43] identified, sequenced and characterized a chromosomal locus of a $14-\mathrm{kb}, w b k$ biosynthesis gene cluster, involved in the LPS O-side-chain biosynthesis of $B$. melitensis $16 \mathrm{M}$. Analysis of the nucleotide sequence revealed the presence of seven open reading frames (ORFs), with six of them showing homology with genes involved in LPS O-side-chain biosynthesis from other organisms, and surrounded by four entire and one partial insertion sequences (IS). The seven ORFs were named according to the bacterial polysaccharide gene nomenclature proposed by Reeves et al. [44]. The GCG Gap program (Wisconsin package version 9.1, Genetic Computer Group, Madison, WI) was used to compare the deduced gene products and their similarity to various protein homologues. Seven genes of the wbk locus of Brucella melitensis $16 \mathrm{M}$ were $w b k A, g m d$, per, $w z m, w z t, w b k B$, and $w b k C$, coding, respectively, for proteins homologous to $\mathrm{N}$ formyl-perosaminyltransferase, GDP-mannose 4,6 dehydratase, perosamine synthetase, ABC-type transporter (integral membrane protein), ABC-type transporter (ATPase domain), a hypothetical protein of unknown function, and a putative formyl transferase [45]. The wzm and $w z t$ (putative the integral membrane component of $\mathrm{ABC}$ transporters) mutation resulted in a rough phenotype of $B$. melitensis $16 \mathrm{M}$ colonies as shown by crystal violet colony staining [43]. The $w z m / w z t$ mutant also failed to react in ELISA on whole cells with MAbs directed against the S-LPS O-side-chain of Brucella species (anti-S-LPS MAbs), confirming the absence of the O-side-chain on the 
Table 2: Genes encoding lipid A biosynthesis in Brucella melitensis I6 M.

\begin{tabular}{|c|c|c|}
\hline Gene & Product & Location/Chromosome I/II \\
\hline LpxA & Acyl-(acyl carrier protein) UDP-N-acetylglucosamine-O acyltransferase & $856881-857729 / 1$ \\
\hline LpxC & UDP-3-O-(3Hydroxymyristoyl) N-acetylglucosamine diacetylase & $608267-609127 / /$ \\
\hline LpxD & UDP-3-O-(3Hydroxymyristoyl) glucosamine $\mathrm{N}$-acetyltransferase & $855363-856418 / 1$ \\
\hline LpxB & Lipid-A-disaccharide synthetase & $858609-859796 / 1$ \\
\hline LpxK & Tetraacyldisaccharide-I-P4'-Kinase & $1067291-1068316 / 11$ \\
\hline KdsA & 2-dehydro-3-deoxyphosphooctonate aldolase & $87665 I-877448 / 1$ \\
\hline KdsB & 3-deoxy-manno octulosanate cytidylyl transferase & $1959311-19601981 / 1$ \\
\hline $\mathrm{KdtA}$ & 3-deoxy-D-manno octulosonic-acid transferase & $1068319-1069659 / 11$ \\
\hline $\mathrm{HtrB}$ & Lauroyl/myristoyl acyltransferase & | | $59853-|| 60776 / \mid$ \\
\hline
\end{tabular}

bacterial surface. Three complete and one incomplete insertion sequences in close association with the wbk gene cluster were found (ISBm1, ISBm, ISBm3, ISBm4). The presence of several ISs in intimate association with the $w b k$ locus is intriguing. Since IS elements are suggested to play an important evolutionary role in mediating chromosomal rearrangements, it seems likely that they might have contributed to the structural evolution and probably horizontal acquisition of the $\mathrm{O}$-antigen biosynthesis gene cluster in Brucella spp.

\section{Mannose (manA, B, C)}

Monreal et al. [46] showed that several LPS genes flank the seven genes described by Godfroid et al.[43]. These genes include manA, $\operatorname{manB}$, and $\operatorname{manC}$, and their position strongly suggests that they act coordinately with gmd and per and independently of other mannose genes. Polymyxin $B$ sensitive mutants were isolated by transposon mutagenesis of $B$. abortus 2308 and screening for viability loss after a controlled exposure to an excess of this antibiotic [47]. Since the O-polysaccharide plays a role in protection against polymyxin $\mathrm{B}$, these mutants were further screened for O-polysaccharide defects by agglutination with anti-S-LPS antibodies. Four mutants negative in this test were then chosen on the basis of their different polymyxin B sensitivities. Computer database analysis revealed that the mini-Tn5 was inserted in the per gene, $w b k A, \operatorname{manB}$ and open reading frame provisionally named $w a^{* *}$. This gene product was a membrane protein of the glycosyltransferase family involved in LPS biosynthesis, but it was different from other putative glycosyltransferases described before as involved in LPS synthesis in Brucella. Monreal et al. [46] did a search in the complete genome sequence of $B$. melitensis $16 \mathrm{M}$ and $B$. suis 1330 and revealed a single homologous genes for per and $w b k A$, both located in the wbk region. The gene homologous to $w a^{* *}$ was also in chromosome I, although in a different region. On the other hand, the $B$. melitensis and $B$. suis man $B$ homologues were in chromosome II, along with a manC gene putatively coding for both mannose-6-P-isomerase and mannose-1-P-guanylyltransferase activities. Since phenotypic analysis revealed a severe core defect in the mutant, the gene was designated $\operatorname{man} B_{\text {core }}$. The genes $w a^{* *}$ and $m a n B_{\text {core }}$ are involved in the biosynthesis of the $B$. abortus LPS core. In contrast to the parental strain, per, $w b k A, w a^{* *}$, and $m a n B_{\text {core }}$ mutants were resistant to the SBrucella-specific phages and sensitive to the R-Brucella-specific phage R/C. Moreover, it was observed that the man$B_{\text {core }}$ mutant showed the lowest $\mathrm{R} / \mathrm{C}$ phage sensitivity and the highest polymyxin $\mathrm{B}$ resistance and that, conversely, the $w a^{* *}$ mutant had the highest $\mathrm{R} / \mathrm{C}$ phage sensitivity and the lowest polymyxin $\mathrm{B}$ resistance.

Besides the antigen-O, the lipid A is the part of the LPS molecule responsible for its endotoxic activity. In $B$. melitensis $16 \mathrm{M}$ (Table 2) and B. suis (Table 3) were already identified some genes involved in lipid A biosynthesis, however mutants for those genes have not been described what makes harder to define the role of these gene products in LPS synthesis.

\section{Interaction between Brucella LPS and host innate immunity}

In contrast to other intracellular pathogens, Brucella species do not produce exotoxins, antiphagocytic capsules or thick cell walls, resistant forms or fimbriae and do not show antigenic variation [48]. A key aspect of the virulence of Brucella is its ability to proliferate within professional and non-professional phagocytic host cells. Therefore, Brucella successfully bypasses the bactericidal effects of phagocytes, and their virulence and chronic infections are thought to be due to their ability to avoid the killing mechanisms of host cells [49]. Some studies with non-professional phagocytes have shown that Brucella invades host cells and is contained within early endosome-like vacuoles. These vacuoles rapidly fuse with early autophagosomes that acquire vacuolar $\mathrm{H}+$-ATPase and lysosome-associated membrane proteins (LAMP) maturing into a late autophagosome. These autophagosomes inhibit fusion with lysosomes and finally become a replicating vacuole normally associated with the endoplasmic reticulum [50,51]. Porte et al. showed that the LPS O-side chain is involved in inhibition of the early fusion between Brucella suis containing phagosomes and lysosomes in 
Table 3: Genes encoding lipid A biosynthesis in Brucella suis.

\begin{tabular}{lll}
\hline Gene & Product & Location/Chromosome I/II \\
\hline LpxA & Acyl-(acyl carrier protein) UDP-N-acetylglucosamine-O acyltransferase & $1130902-113$ I738/I \\
LpxC & UDP-3-O-Acyl-N-acetylglucosamine diacetylase & $1379039-1379899 / I$ \\
LpxD & UDP-3-O-(3Hydroxymyristoyl) glucosamine N-acetyltransferase & $1132213-1133268 / /$ \\
LpxB & Lipid-A-disaccharide synthetase & $1128835-1130022 / I$ \\
LpxK & Tetraacyldisaccharide-I-P4'-Kinase & $202326-20335 I / I I$ \\
KdsA & 2-dehydro-3-deoxyphosphooctonate aldolase & $1111145-1111978 / I$ \\
KdsB & 3-deoxy-manno octulosanate cytidylyl transferase & $43162-43917 / I$ \\
KdtA & 3-deoxy-D-manno octulosonic-acid transferase & $200983-202323 / I I$ \\
HtrB & Lauroyl acyltransferase & $824862-825788 / I$ \\
\hline
\end{tabular}

murine macrophages at least during the first few hours after phagocytosis [52]. In contrast, the phagosomes containing rough mutants, which fail to express the O-antigen, rapidly fuse with lysosomes. The LPS O-chain might be a major factor that governs the early behavior of bacteria inside macrophages.

Recognition of the presence of LPS by cells such as monocytes and macrophages has evolved over centuries to provide the mammalian host with a rapid recognition of and reaction towards Gram-negative infection. This rapid, innate response against LPS typically involves the release of a range of pro-inflammatory mediators, such as TNF- $\alpha$, IL-6, IL-12 and IL-1 $\beta$, which in local sites of infection and in moderate levels benefit the host greatly by promoting inflammation and otherwise priming the immune system to eliminate the invading organisms. However, in conditions where the body is exposed to LPS excessively or systemically (as when LPS enters the blood stream), a systemic inflammatory reaction can occur, leading to multiple organ failure, shock and potentially death [53].

Recognition of bacterial LPS is mediated by CD14, however, CD14 lacks transmembrane and intracellular domains necessary for signal transduction and thus requires the involvement of molecules belonging to the TLR family. The recent discovery of TLR proteins, a family of mammalian pattern recognition receptors, has provided new insights into our understanding of the mechanisms by which Brucella can elicit cellular responses from innate immune cells. B. abortus induces interleukin (IL)12 production from human monocytes and this effect was blocked by anti-CD14 antibody, suggesting that the Brucella binding and/or signaling to monocytes was mediated via LPS [54]. Additionally, Brucella's ability to elicit IL-12 secretion enables it to drive Th0 cells to differentiate into Th1 effector and memory cells that are a central feature of the potential use of $B$. abortus as a vaccine carrier and adjuvant.

Our group has investigated the ability of $B$. abortus and its purified LPS and lipid A to trigger TLR2 and TLR4 and the impact of this activation in innate recognition and elimination of invading bacteria [55]. CHO reporter cell lines transfected with CD14 and TLRs showed that B. abortus triggers both TLR2 and TLR4. In contrast, lipopolysaccharide (LPS) and lipid A derived from Brucella rough (R) and smooth (S) strains activate CHO cells only through TLR4. Consistently, macrophages from $\mathrm{C} 3 \mathrm{H} / \mathrm{HePas}$ mice exposed to R and S strains and their LPS produced higher levels of tumor necrosis factor alpha (TNF- $\alpha$ ) and interleukin-12 compared to C3H/HeJ, a TLR4 mutant mouse. The essential role of TLR4 for induction of proinflammatory cytokines was confirmed with diphosphoryl lipid A from Rhodobacter sphaeroides. Furthermore, to determine the contribution of TLR2 and TLR4 in bacterial clearance, numbers of Brucella were monitored in the spleen of $\mathrm{C} 3 \mathrm{H} /$ $\mathrm{HeJ}, \mathrm{C} 3 \mathrm{H} / \mathrm{HePas}, \mathrm{TLR} 2$ knockout, and wild-type mice at 1 , 3 , and 6 weeks following $B$. abortus infection. Interestingly, murine brucellosis was markedly exacerbated at weeks 3 and 6 after infection in animals that lacked functional TLR4 $(\mathrm{C} 3 \mathrm{H} / \mathrm{HeJ})$ compared to $\mathrm{C} 3 \mathrm{H} / \mathrm{HePas}$ that paralleled the reduced gamma interferon production by this mouse strain. By mass spectrometry analysis we found dramatic differences on the lipid A profiles of $\mathrm{R}$ and $\mathrm{S}$ Brucella strains when compared to E. coli lipid A (Figure 2). As shown in Figure 2, Brucella rough and smooth lipid A possess more heptaacylated species than $E$. coli lipid A that presents more hexaacylated residues. In conclusion, these results indicate that TLR4 plays a role in resistance to $B$. abortus infection. In contrast, Giambartolomei et al [56] claimed that lipoproteins Omp19 and Omp16 signaling through TLR2 rather than LPS are the key molecules involved in the proinflammatory response mediated by IL- 6 and TNF- $\alpha$ observed during Brucella infection. This phenomenon seems to be related to the lipid moiety of the proteins. Therefore, TLR2 and TLR4 signaling during Brucella infection are mediated by two different ligands, lipoproteins and LPS, respectively. More recently, Weiss et al. [57] found that during infection of macrophages, Brucella avoids activation of TLR4 at six hours but activates TLR4, TLR2, and MyD88 (myeloid differentiation factor 88 ) at 24 hours postinfection. Interestingly, even though its activation is delayed, among the three MyD88 is the 

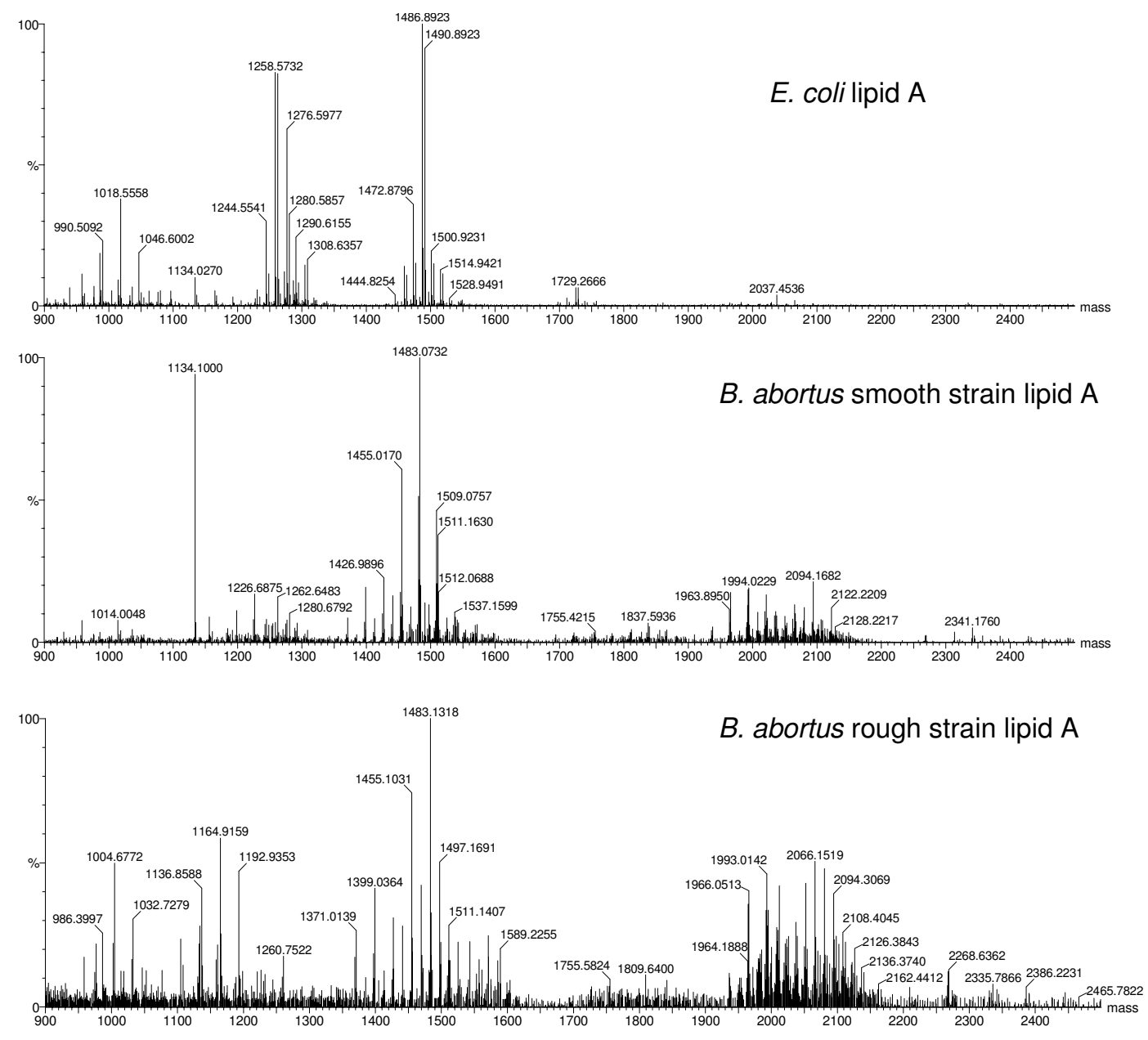

Figure 2

Mass spectrometry analysis of lipid A species from Brucella abortus smooth and rough strains and from Escherichia coli.

most important molecule for host defense against Brucella infection in vivo, since MyD88 knockout (KO) mice are more susceptible to infection when compared to TLR4, TLR2, TLR4/TLR2 KO mice. These findings open the possibility for the involvement of other TLRs that signal through MyD88 in host resistance against Brucella infection. As a matter of fact, Huang et al. [58] demonstrated that HKBA (heat-killed Brucella abortus) stimulates dendritic cells (DC) via TLR9 to secrete IL-12. Furthermore, this effect can be stimulated by DNA derived from HKBA and can be blocked by addition of suppressive oligodeoxynucleotides (ODNs). The consequence of TLR9 engagement is that Th1-like responses such as IFN-g production takes place in wild-type but not TLR9 KO mice.

\section{Acknowledgements}

This work was supported by CNPq (Conselho Nacional de Desenvolvimento Científico e Tecnológico) and FAPEMIG (Fundação de Amparo a Pesquisa no Estado de Minas Gerais).

\section{References}

I. Young EJ: An overview of human brucellosis. Clin Infect Dis 1995, 21:283-289.

2. Corbel MJ, Brinley-Morgan WJ: Genus Brucella. In Bergey's Manual of Systematic Bacteriology Volume I. Edited by: Krieg NR, Holt JG. The Williams \& Wilkins, Baltimore; 1984:377-388.

3. Blasco JM: Brucella ovis. In Animal brucellosis Edited by: Nielsen K, Duncan JR. Boca Raton, FL: CRC Press; 1990:351-78.

4. Davis DS: Brucellosis in Wildlife. In Animal Brucellosis Edited by: Nielsen K, Duncan JR. CRC Press, Boca Raton, FL; 1990:32I-334.

5. Cloeckaert A, Verger JM, Grayon M, Paquet JY, Garin-Bastuji B, Foster G, Godfroid J: Classification of Brucella spp. isolated from marine mammals by DNA polymorphism at the omp2 locus. Microbes Infect 200I, 3:729-738.

6. Cloeckaert A, Grayon M, Grépinet O, Boumedine KS: Classification of Brucella strains isolated from marine mammals by infrequent restriction site-PCR and development of specific PCR identification tests. Microbes Infect 2003, 5:593-602.

7. Alton GG, Jones LM, Angus RD, Verger JM: Techniques for the Brucellosis Laboratory. Institut National de la Recherche Agronomique, Paris 1988.

8. Guihot A, Bossi P, Bricaire F: Bioterrorism with brucellosis. Presse Med 2004, 33: 1 19-22. 
9. Lapaque N, Moriyon I, Moreno E, Gorvel JP: Brucella lipolysaccharide acts as a virulence factor. Current Opinion in Microbiology 2005, 8:60-66.

10. Bundle DR, Cherwonogrodzky JW, Gidney MAJ, Meikle PJ, Perry MB, Peters T: Definition of Brucella $A$ and $M$ epitopes by monoclonal typing reagents and synthetic oligosaccharides. Infect Immun 1989, 57:2829-2836.

II. Moreno E, Stackebrandt E, Dorsch M, Wolters J, Busch M, Mayer H: Brucella abortus I6S rRNA and lipid A reveal phylogenetic relationship with members of the alpha-2 subdivision of the class Proteobacteria. J Bacteriol 1990, 172:3569-3576.

12. Raetz CRH: Bacterial lipopolysaccharides: a remarkable family of bioactive macroamphiphiles. In Escherichia coli and Salmonella Volume I. Edited by: Neidhardt FC. Cellular and Molecular Biology; 1996: 1035-1063.

13. Ramos-Sánchez MC, Orduña-Domingo A, Rodríguez Tones A, Martin-Gil F], Martin-Gi J: Investigations on thermotropic phase behavior of lipids A from Brucella and other Gram-negative bacteria. Thermochim Acta 1992, 144:299-305.

14. Rojas N, Freer E, Weintreub A, Ramfrez M, Lind S, Moreno E: Immunochemical identification of Brucella abortus lipopolysaccharide epitopes. Clin Diagn Lab Immunol 1994, I:206-2I3.

15. Freer E, Rojas N, Weintraub A, Lindberg AA, Moreno E: Heterogeneity of Brucella abortus lipopolysaccharides. Res Microbiol 1995, I 46:569-578.

16. Raetz CR: Biochemistry of endotoxins. Annu Rev Biochem 1990, 59:129-170.

17. Díaz-Aparicio E, Aragón V, Marín C, Alonso B, Font M, Moreno E, Pérez-Ortiz S, Blasco JM, Diaz R, Moriyón I: Comparative analysis of Brucella serotypes A and $M$ and Yersinia enterocolitica O:9 polysaccharides for serological diagnosis of brucellosis in cattle, sheep, and goats. J Clin Microbiol I993, 31:3 I36-3I4I.

18. DelVecchio VG, Kapatral V, Redkar RJ, Patra G, Mujer C, Los T, Ivanova N, Anderson I, Bhattacharyya A, Lykidis A, Reznik G, Jablonski L, Larsen N, D'Sousa M, Bernal A, Mazur M, Goltsman E, Selkov E, Elzer PH, Hagius S, O'Callaghan D, Letesson JJ, Haselkorn R, Kyrpides $\mathrm{N}$, Overbeek $\mathrm{R}$ : The genome sequence of the facultative intracellular pathogen Brucella melitensis. Proc Natl Acad Sci U S A 2002, 99:443-448.

19. Paulsen IT, Seshadri R, Nelson KE, Eisen JA, Heidelberg JF, Read TD, Dodson RJ, Umayam L, Brinkac LM, Beanan MJ, Daugherty SC, Deboy RT, Durkin AS, Kolonay JF, Madupu R, Nelson WC, Ayodeji B, Kraul M, Shetty J, Malek J, Van Aken SE, Riedmuller S, Tettelin H, Gill SR, White O, Salzberg SL, Hoover DL, Lindler LE, Halling SM, Boyle SM, Fraser CM: The Brucella suis genome reveals fundamental similarities between animal and plant pathogens and symbionts. Proc Natl Acad Sci USA 2002, 99: 13 | 48 - 13153.

20. Halling SM, Peterson-Burch BD, Bricker BJ, Zuerner RL, Qing Z, Li LL, Kapur V, Alt DP, Olsen SC: Completion of the genome sequence of Brucella abortus and comparison to the highly similar genomes of Brucella melitensis and Brucella suis. J Bacteriol 2005, 8:2715-2726.

21. DelVecchio VG, Kapatral V, Elzer P, Patra G, Mujer CV: The genome of Brucella melitensis. Vet Microbiol 2002, 90:587-592.

22. Dricot A, Rual JF, Lamesch P, Bertin N, et al.: Generation of the Brucella melitensis ORFeome Version I.I. Genome Research 2004, I 4:220I-2206

23. Delrue RM, Lestrate P, Tibor A, Letesson J], De Bolle X: Brucella pathogenesis, genes identified from random large-scale screens. FEMS Microbiol Lett 2004, 23 I: I-1 2.

24. Vizcaino N, Cloeckaert A, Zygmunt MS, Fernandez-Lago L: Characterization of a Brucella species 25-kilobase DNA fragment delected from Brucella abortus reveals a large gene cluster related to the synthesis of a polysaccharide. Infect Immun 200I, 69:6738-6748.

25. Riley LK, Robertson DC: Brucellacidal activity of human and bovine polymorphonuclear leukocyte granule extracts against smooth and rough strains of Brucella abortus. Infect Immun 1984, 46:231-236.

26. Schurig GG, Roop RM, Bagchi T, Boyle S, Buhrman D, Sriranganathan $\mathrm{N}$ : Biological properties of $\mathrm{RB} 5 \mathrm{I}$; a stable rough strain of Brucella abortus. Vet Microbiol I991, 28: 171-188.

27. Allen CA, Adams LG, Ficht TA: Transposon-derived Brucella abortus rough mutants are attenuated and exhibit reduced intracellular survival. Infect Immun 1998, 66:1008-1016.
28. Winter AJ, Schurig GG, Boyle SM, Sriranganathan NJ, Bevins S, Enright FM, Elzer PH, Kope JD: Protection of BALB/c mice against homologous and heterologous species of Brucella by rough strain vaccines derived from Brucella melitensis and Brucella suis biovar 4. Am J Vet Res 1996, 57:677-683.

29. Stevens MG, Olsen SC, Pugh GW Jr, Brees D: Comparison of immune responses and resistance to brucellosis in mice vaccinated with Brucella abortus 19 and RB5I. Infect Immun 1995, 63:264-270.

30. Godfroid F, Taminiau B, Danese I, Denoel P, Tibor A, Weynants V, Cloeckaert A, Godfroid J, Letesson JJ: Identification of the perosamine synthetase gene of Brucella melitensis $16 \mathrm{M}$ and involvement of lipopolysaccharide $\mathbf{O}$ side chain in Brucella survival in mice and in macrophages. Infect Immun 1998, 66:5485-5493.

31. Stroeher UH, Karageorgos LE, Brown MH, Morona R, Manning PA: A putative pathway for perosamine biosynthesis is the first function encoded within the rfb region of Vibrio cholerae $\mathrm{OI}$. Gene 1995, 166:33-42.

32. Zygmunt MS, Dubray G, Bundle DR, Perry MP: Purified native haptens of Brucella abortus $B I 9$ and $B$. melitensis $16 \mathrm{M}$ reveal the lipopolysaccharide origin of the antigens. Ann Inst Pasteur Microbiol 1988, 139:42I-433.

33. Hong PC, Tsolis RM, Ficht TA: Identification of genes required for chronic persistence of Brucella abortus in mice. Infect Immun 2000, 68:4102-4I07.

34. Kido N, Ohta M, lida KI, Hasegawa T, Ito H, Arakawa Y, Komatsu T, Kato N: Partial deletion of the cloned $r f b$ gene of Escherichic coli 09 results in synthesis of a new $O$-antigenic lipopolysaccharide. J Bacteriol 1989, I 1 1:3629-3633.

35. McQuiston JR, Vemulapalli R, Inzana TJ, Schurig GG, Sriranganathan N, Fritzinger D, Hadfield TL, Warren RA, Snellings N, Hoover D, Halling S, Boyle SM: Genetic Characterization of a Tn 5-Disrupted glycosyltransferase gene homolog in Brucella abortus and its effect on lipopolysaccharide composition and virulence. Infect Immun 1999, 99:3830-3835.

36. Vemulapalli R, McQuiston JR, Schurig GG, Sriranganathan N, Halling SM, Boyle SM: Identification of an IS7 I I element interrupting the wboA gene of Brucella abortus vaccine strain RB5I and a PCR assay to distinguish strain RB5 I from other Brucella species and strains. Clin Diagn Lab Immunol I 999, 5:760-764.

37. Vemulapalli R, He Y, Buccolo LS, Boyle SM, Sriranganathan N, Schurig GG: Complementation of Brucella abortus RB5 I with a functional wboA gene results in $O$-antigen synthesis and enhanced vaccine efficacy but no change in rough phenotype and attenuation. Infect Immun 2000, 7:3927-3932.

38. Fernandez-Prada CM, Nikolich M, Vemulapalli R, Sriranganathan $N$, Boyle SM, Schurig GG, Hadfield TL, Hoover DL: Deletion of wboA enhances activation of the lectin pathway of complement in Brucella abortus and Brucella melitensis. Infect Immun 200I, 7:4407-44I6.

39. Fernandez-Prada CM, Zelazowska EB, Nikolich M, Hadfield TL, Roop RM 2nd, Robertson GL, Hoover DL: Interactions between Brucella melitensis and human phagocytes: bacterial surface 0 polysaccharide inhibits phagocytosis, bacterial killing, and subsequent host cell apoptosis. Infect Immun 2003, 71:2 II0-9.

40. Vizcaino N, Caro-Hernandez P, Cloeckaert A, Fernandez-Lago L: DNA polymorphism in the omp25/omp3 I family of Brucella spp. : identification of a I.7-kb inversion in Brucella cetaceae and of a I5.I-kb genomic island, absent from Brucella ovis, related to the synthesis of smooth lipopolysaccharide. Microbes Infect 2004, 6:82I-834.

4I. Ugalde JE, Czibener C, Feldman MF, Ugalde RA: Identification and characterization of the Brucella ab ortus phosphoglucomutase gene: role of lipopolysaccharide in virulence and intracellular multiplication. Infect Immun 2000, 68:5719-5723.

42. Ugalde JE, Comerci DJ, Leguizamon MS, Ugalde RA: Evaluation of Brucella abortus phosphoglucomutase (pgm) mutant as a new live rough-phenotype vaccine. Infect Immun 2003, $71: 6264-9$.

43. Godfroid F, Cloeckaert A, Taminiau B, Danese I, Tibor A, De Bolle X, Mertens $P$, Letesson J]: Genetic organization of the lipopolysaccharide $\mathbf{0}$-antigen biosynthesis region of Brucella melitensis $\mathbf{I} 6$ M (wbk). Res Microbiol 2000, I5 I:655-668.

44. Reeves PR, Hobbs M, Valvano MA, Skurnik M, Whitfield C, Coplin D Kido D, Klena NJ, Maskel D, Raetz CRH, Rick PD: Bacterial 
polysaccharide synthesis and gene nomenclature. Trends Microbiol 1996, 4:495-503.

45. Cloeckaert A, Grayon M, Verger JM, Letesson JJ, Godfroid F: Conservation of seven genes involved in the biosynthesis of the lipopolysaccharide O-side chain in Brucella spp. Res Microbiol 2000, I 5 I:209-16.

46. Monreal D, Grillo MJ, Gonzalez D, Marin CM, De Miguel MJ, LopezGoni I, Blasco JM, Cloeckaert A, Moriyon I: Characterization of Brucella abortus O-polysaccharide and core lipopolysaccharide mutants and demonstration that a complete core is required for rough vaccines to be efficient against Brucella abortus and Brucella ovis in the mouse model. Infect Immun 2003, 6:326I-7I.

47. Sola-Landa A, Pizarro-Cerdo J, Grilló MJ, Moreno E, Morrión I, Blasco JM, Gorvel JP, López-Goñi I: A two-component regulatory system playing a critical role in plant pathogen and endosymbionts is present in Brucella abortus and controls cell invasion and virulence. Mol Microbiol 1998, 29:125-138.

48. Finlay B, Falkow S: Common themes in microbial pathogenicity. Microbiol Mol Biol Rev 1997, 6I:136-169.

49. Pizarro-Cerda J, Meresse S, Parton RG, van der Goot G, Sola-Landa A, Lopez-Goni I, Moreno E, Gorvel JP: Brucella abortus transits through the autophagic pathway and replicates in the endoplasmic reticulum of nonprofessional phagocytes. Infect Immun 1998, 66:57| I-5724.

50. Pizarro-Cerda J, Moreno E, Sanguedolce V, Mege JL, Gorvel JP: Virulent Brucella abortus prevents lysosome fusion and is distributed within autophagosome-like compartments. Infect Immun 1998, 66:2387-2392.

5I. Dorn BR, Dunn WA Jr, Progulske-Fox A: Bacterial interactions with the autophagic pathway. Cell Microbiol 2002, 4:I-10.

52. Porte F, Naroeni A, Ouahrani-Bettache S, Liautard JP: Role of the Brucella suis lipopolysaccharide $O$ antigen in phagosomal genesis and in inhibition of phagosome-lysosome fusion in murine macrophages. Infect Immun 2003, 7 I: | 48I-I 490.

53. Erridge $C$, Bennett-Guerrero $E$, Poxton IR: Structure and function of lipopolysaccharides. Microbes and Infection 2002, 4:837-85I.

54. Zaitseva M, Golding H, Manischewitz J, Webb D, Golding B: Brucella abortus as a potential vaccine candidate: induction of interleukin- $I 2$ secretion and enhanced B7.I and B7.2 and intercellular adhesion molecule I surface expression in elutriated human monocytes stimulated by heat-inactivated $B$. abortus. Infect Immun 1996, 64:3 109-3II9.

55. Campos MA, Rosinha GM, Almeida IC, Salgueiro XS, Jarvis BW, Splitter GA, Qureshi N, Bruna-Romero O, Gazzinelli RT, Oliveira SC: Role of Toll-Like Receptor 4 in Induction of Cell-Mediated Immunity and Resistance to Brucella abortus Infection in Mice. Infect Immun 2004, I:176-I86.

56. Giambartolomei GH, Zwerdling A, Cassataro J, Bruno L, Fossati CA, Philipp MT: Lipoprotein, not lypopolysaccharide, are the key mediators of the proinflammatory response elicited by heatkilled Brucella abortus. J Immunol 2004, 173:4635-4642.

57. Weiss DS, Takeda K, Akira S, Zychlinski A, Moreno E: MyD88, but not toll-like receptors 4 and 2 , is required for efficient clearance of Brucella abortus. Infect Immun 2005, 73:5।37-5I43.

58. Huang L, Ishii KJ, Akira S, Aliberti J, Golding B: Th I-like cytokine induction by heat-killed Brucella abortus is dependent on triggering of TLR9. J Immunol 2005, 175:3964-3970.

\section{Publish with Biomed Central and every} scientist can read your work free of charge

"BioMed Central will be the most significant development for disseminating the results of biomedical research in our lifetime. "

Sir Paul Nurse, Cancer Research UK

Your research papers will be:

- available free of charge to the entire biomedical community

- peer reviewed and published immediately upon acceptance

- cited in PubMed and archived on PubMed Central

- yours - you keep the copyright
BioMedcentral 